\title{
Convection Heat Transfer Analysis in a Channel with an Open Trapezoidal Cavity: Heat Source Locations effect
}

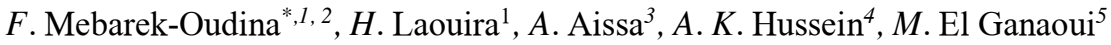 \\ ${ }^{1}$ Department of Physics, Faculty of Sciences, University of 20 août 1955- Skikda, Algeria. \\ ${ }^{2}$ LEAP Laboratory, Department of Mechanical Engineering, University of Mentouri-Constantine 1, Route de Ain El. Bey, Constantine, \\ Algeria. \\ ${ }^{3}$ Laboratoire de Physique Quantique de la Matière et Modélisation Mathématique (LPQ3M), University of Mascara, Algeria. \\ ${ }^{4}$ Mechanical Engineering Department, College of Engineering, University of Babylon, Babylon City, Iraq. \\ ${ }^{5}$ Laboratoire énergétique de Longwy (FJV/LERMAB), Université de Lorraine,
}

\begin{abstract}
In this work, a numerical study of mixed convection inside a horizontal channel with an open trapezoidal enclosure subjected to a discrete heat source in different locations is carried out. The heat source with the length of $\varepsilon=0.75$, is maintained at a constant temperature. The air flow with a fixed velocity and a cold temperature enters the channel horizontally. The other walls of the enclosure and the channel are adiabatic. The results are presented in the form of the contours of velocity, isotherms and Nusselt numbers profiles for various heat source locations, Prandtl number $(\operatorname{Pr}=0.71)$ and Reynolds number $(\operatorname{Re}=100)$ respectively. The distribution of the isotherms depends significantly on the position of the heat source. We noted that the best heat transfer is detected where the heat source is placed in the top of the left .
\end{abstract}

\section{INTRODUCTION}

In this the last five years, the mixed convection phenomena in a channel incorporated an open cavity is the subject problem interest for many researchers. This is due its applications in various industrial sectors. Such as solar receivers, petroleum reservoirs, landing gear wells, crystal growths, geothermal energy systems, float glass production, packaging of semiconductors and electronic chips [1-12]. In fact, the characteristics of heat transfer and the flow field for the mixed. Convection problem in a combination of cavity channel are investigated.

Gourari et al. [12] presented a study of convective flow between two coaxial inclined cylinders, where the inner cylinder generates a constant heat source. They found that, his improvement of heat transfer with increasing Rayleigh number, and the best heat transfer is detected for the inclination angle $90^{\circ}$. Laouira et al. [13] used the simulation software ANSYS to carry out the numerical study of heat transfer in a horizontal channel with an open trapezoidal enclosure subjected to a heat source lengths $(0.16 \leq \varepsilon \leq 1)$. The length of the heat source affects the distribution of the isotherms. Also they found that the local and average Nusselt numbers increase with increasing length of the local heat source.

Manca et al. [14] studied numerically the convection of the air entered horizontal channel, with a constant heat flux at three different locations of the open cavity placed at the lower region of the channel. The best heat transfer is detected for the opposing forced flow configuration. Manca et al. [15]. Experimentally studied the combined convection of the air entered the channel from its left side. An open cavity is placed at bottom wall of the channel. The improvement of the heat transfer with the increase of the ratio of the length to the height of the cavity. Also, for same problem, but the air flow entered the channel from its opposite side Manca et al. [16] investigated the convection phenomena. Aminossadati and Ghasemi [17]. Found that the best location of the heat source is in the right sidewall of the cavity. Buonomo et al. [18] carried out a numerical study of the transient laminar mixed convection in a horizontal channel with an open U-shaped cavity at its bottom region. The cavity is heated from its left sidewall by a uniform heat flux and their others walls (cavity and the channel) are assumed adiabatic. The system is filled with a fluid-saturated porous medium where the air is fluid phase and the Aluminium metal foam is solid phase. The total Nusselt number and the average temperature of the walls showed strong variations at the start.

Sabbar et al. [19] analysed numerically the transient mixed convection in a cavity-channel assembly due to the interaction between the fluid flow and an elastic walls. The open cavity is subjected to a constant heat source from below. They found that the heat transfer rate is enhanced by the existence of the elastic wall (s). Recently, Garcia et al. [20] presented a numerical simulation of the transient mixed convection in an inclined rectangular channel with two facing identical open cubic cavities subjected to an isothermal and discrete heat. They concluded that the Nusselt number increases with the Reynolds number for fixed values of

\footnotetext{
* Corresponding author: author@e-mail.org
} 
the Richardson number. Several references [21-29] deal with mixed convection in an open enclosure- channel assembly.

In our knowledge there is a lack of literature on mixed convection in an open enclosure-channel assembly (complicated cavity). In this paper, the mixed convection in a channel with an open trapezoidal cavity subjected to a heat source of different locations is studied numerically. Cold air enters a channel horizontally. The discrete heat source of length $(\varepsilon=0.75)$ is placed at various locations on the walls of the open cavity.

\section{Geometry and mathematical model}

The geometry of the problem is illustrated in Figure (1). The flow is driven by the air flow flowing through a channel connected to the horizontal top wall of the cavity. The height of the cavity is $(\mathrm{H})$. The free length of the channel beyond the cavity is taken to be $(4 \mathrm{H})$. The heat source of length (LH) is embedded to the lower wall of the cavity and maintained at a constant temperature (Th). An air flow enters the channel horizontally with a cold temperature $(\mathrm{Tc})$, while the other walls are assumed adiabatic. The width of the open upper wall of the cavity is twice that of the lower wall. [13].

The flow is laminar, incompressible and twodimensional; the power of external forces is negligible and Newtonian fluid is the simplifying assumptions used for this study.

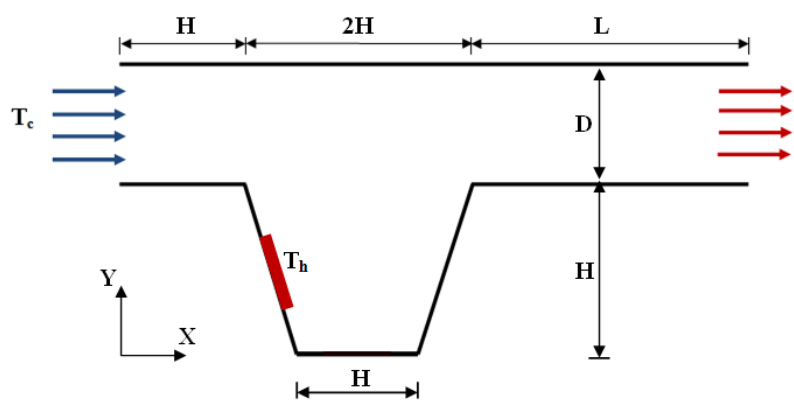

Fig. 1 Geometry of the problem.

The governing equations are written as: [13]

$$
\begin{gathered}
\frac{\partial U}{\partial X}+\frac{\partial V}{\partial Y}=0 \\
U \frac{\partial U}{\partial X}+V \frac{\partial V}{\partial Y}=-\frac{\partial P}{\partial X}+\frac{1}{\operatorname{Re}_{i n}}\left(\frac{\partial^{2} U}{\partial X^{2}}+\frac{\partial^{2} U}{\partial y^{2}}\right) \\
U \frac{\partial V}{\partial X}+V \frac{\partial V}{\partial Y}=-\frac{\partial P}{\partial X}+\frac{1}{\operatorname{Re}_{i n}}\left(\frac{\partial^{2} V}{\partial X^{2}}+\frac{\partial^{2} V}{\partial y^{2}}\right)
\end{gathered}
$$

$$
U \frac{\partial \theta}{\partial X}+V \frac{\partial \theta}{\partial Y}=\frac{1}{\operatorname{Re}_{i n} \operatorname{Pr}}\left(\frac{\partial^{2} \theta}{\partial X^{2}}+\frac{\partial^{2} \theta}{\partial Y^{2}}\right)
$$

Where:

$\mathrm{Re}_{i n}=\frac{\rho u_{i n} H}{\mu}, ; R_{i}=\frac{g H \beta\left(T_{h}-T_{c}\right)}{u_{i n}^{2}} ; \operatorname{Pr}=\frac{v}{\alpha}$

Are the Reynolds number, Richardson number and Prandtl number, respectively.

The another can be defined as:

$$
\begin{gathered}
\theta=\frac{T-T_{c}}{T_{h}-T_{c}} ; U=\frac{u}{u_{i n}} ; V=\frac{v}{u_{i n}} ; X=\frac{x}{H} ; Y=\frac{y}{H} ; \\
P=\frac{p}{\rho u_{i n}^{2}} ; \varepsilon=\frac{L_{H}}{H}
\end{gathered}
$$

Are dimensionless variables used in this investigation.

The average Nusselt number is computed by:

$$
\begin{gathered}
N_{u}(X)=\frac{1}{L_{H}} \int_{0}^{L_{H}} N_{u}(X) d Y \\
N_{u}(X)=\frac{h(X) X}{\lambda}, \text { is the local Nusselt number. } \\
h(X)=\frac{Q}{T_{h}(X)-T_{i}}
\end{gathered}
$$

The boundary conditions are given as: [13]

Channel entrance:

$$
\begin{aligned}
\mathrm{X} & =0, \mathrm{H} \leq \mathrm{Y} \leq \mathrm{H}+\mathrm{D}, \theta=0, \mathrm{U}_{\text {in }}=1 \\
\frac{\partial \theta}{\partial X} & =\frac{\partial U}{\partial X}=\frac{\partial V}{\partial Y}=0, P=0
\end{aligned}
$$

On the heater: $\theta=1$, otherwise, $\frac{\partial \theta}{\partial n}=0$, where (n) is the normal vector.

On the solid fixed walls: $\quad \mathrm{U}=\mathrm{V}=0$.

\section{Numerical simulations}

The results of this study are obtained using ANSYS software [13]. This work is validated by the results of Manca et al. [15]. For brevity, the study of the grid test 
with validation is not provided here and it is presented in detail in our recent article [13].

\section{4 results \& discussion}

In this part the results are presented in form of isotherm contours and the Nusselt number and discussed for various values of Richardson number $(0.1 \leq \mathrm{Ri} \leq 100)$ for heat source length [ $\varepsilon=0.75]$. Both Reynolds and Prandtl numbers are kept constant at $(\operatorname{Re}=100)$ and $(\operatorname{Pr}=0.71)$ respectively.

\subsection{Effect of the heat source location on the isotherm contours}

Figures (2-9), show the isotherm contours for various locations of heat source and Richardson number $(\mathrm{Ri}=1)$. The three different modes of heat transfer are observed in different regions. It can be observed from the results, that these contours try to distribute rapidly and strongly inside the enclosure as the heat source location change. The intense accumulation of the isotherms can be seen especially in the heat source location at the wall of the open trapezoidal enclosure. This is a normal and expected result, since the longer heat source leads to increase the heat generation rate inside the enclosure. This causes to increase significantly the convection effects as a result of increasing the buoyancy force. From the side, the highest rate of the heat generation leads to increase the heat source surface temperature and as a result the natural convection effect becomes more severe when the heat source length increases. In addition, it can be seen that the heat source on the bottom wall transfers most heat into the cold air entering the channel due to the large temperature difference between them. This can be detected from the isotherms accumulated close to the exit of the channel. From the previous discussion, it can be deduced that the location of the heat source leads to a signification variation in the pattern of the isotherm contours.

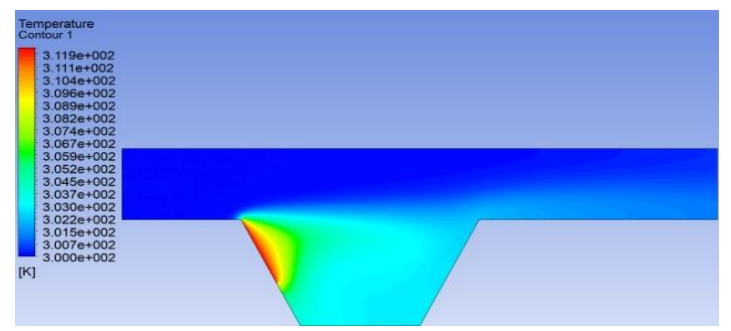

Fig. 2 Contours of the isotherms for position 1.

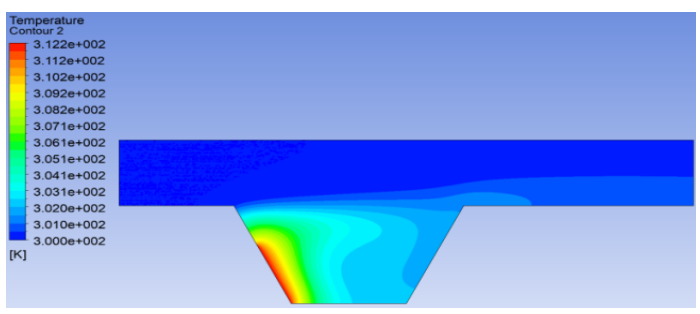

Fig. 3 Contours of the isotherms for position 2.

\begin{tabular}{|c|c|c|c|c|}
\hline Ri & Post.1 & Post.2 & Post.3 & Post.4 \\
\hline 0,1 & 0,27005612 & 0,17162815 & 0,20797856 & 0,17155011 \\
\hline 1 & 1,46512041 & 0,86506075 & 1,02959558 & 0,93070196 \\
\hline 10 & 2,65488756 & 1,55174809 & 1,85609339 & 1,66949578 \\
\hline 100 & 2,86271187 & 1,68554648 & 2,01613497 & 1,81344737 \\
\hline
\end{tabular}

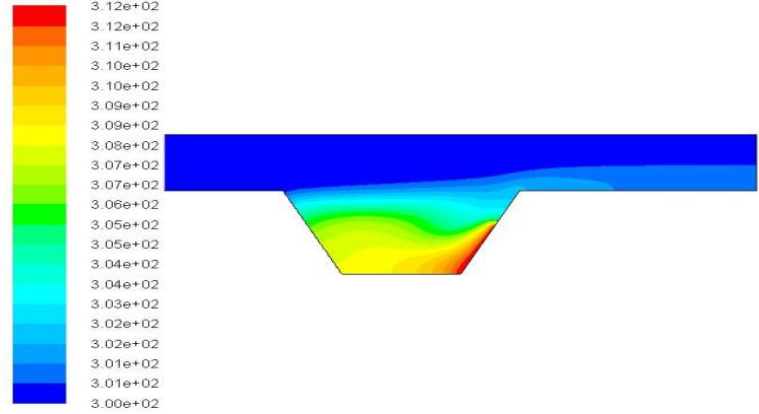

Fig. 4 Contours of the isotherms for position 3.
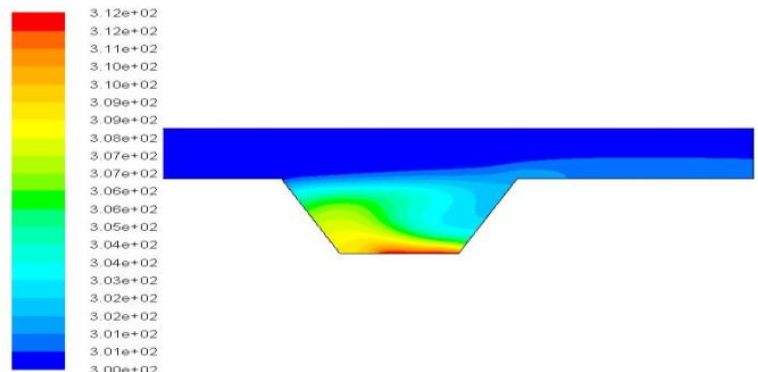

Fig. 5 Contours of the isotherms for position 4.

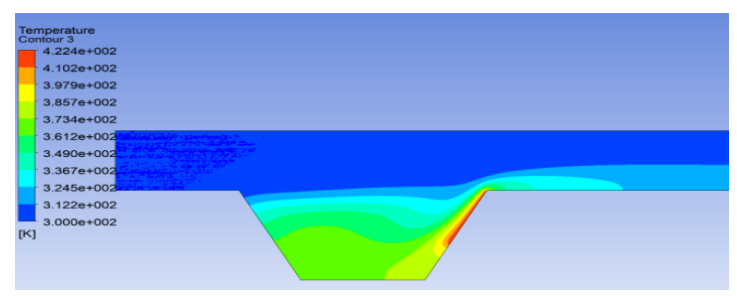

Fig. 6 Contours of the isotherms for position 5

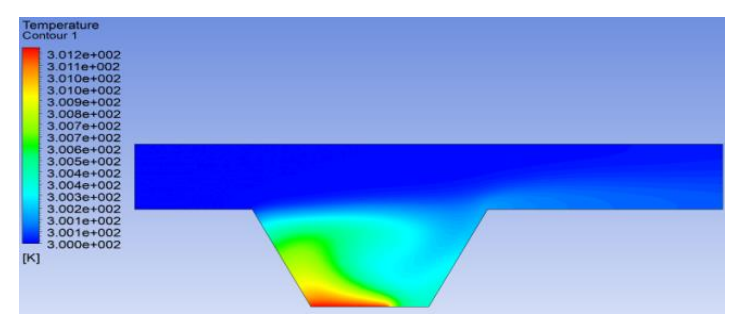

Fig. 7 Contours of the isotherms for position 6

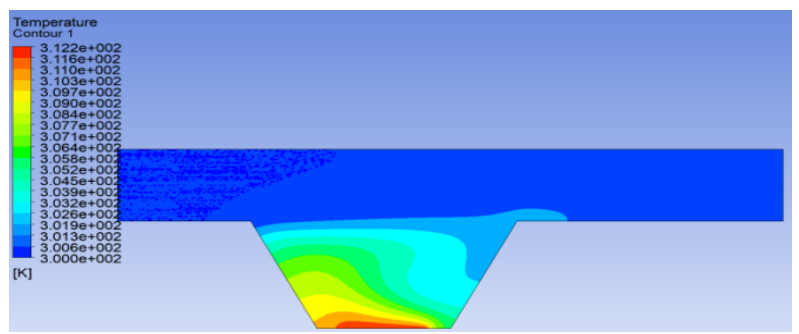

Fig. 8 Contours of the isotherms for position 7. 


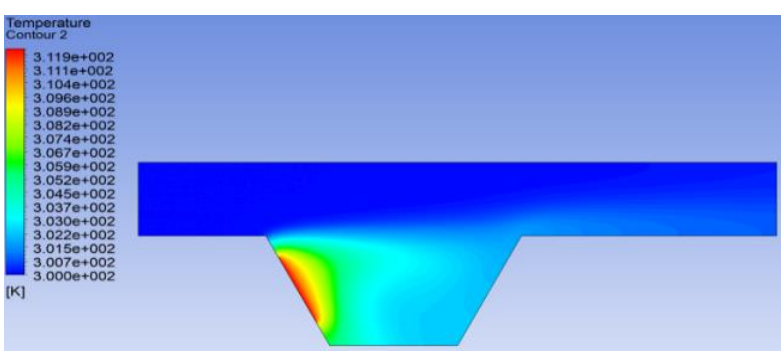

Fig. 9 Contours of the isotherms for position 8 .

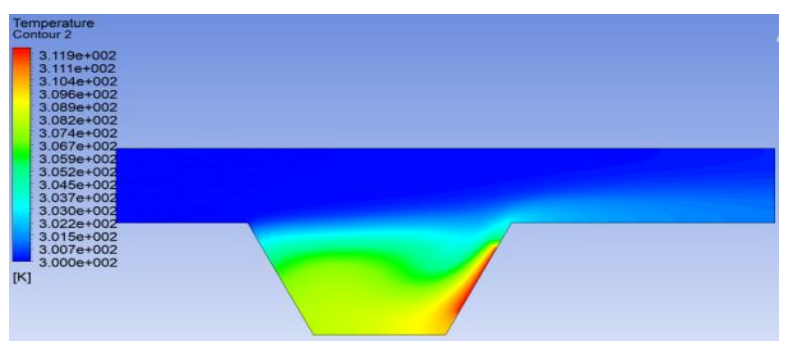

Fig. 10 Contours of the isotherms for position 9.

\subsection{Effect of the heat source location on the Nusselt number}

Table 1 and Figs. 11-13 display the variation of the average Nusselt number with various locations of heat source and Richardson number. It can be seen from the results that as the heat source location changes the average Nusselt number changes too. It can be seen that the maximum value of the average Nusselt number corresponds to the heat source location on the top of the left wall followed with location on the top of the right wall (position 1). The weak heat transfer is detected in the middle of the bottom wall (position 7).

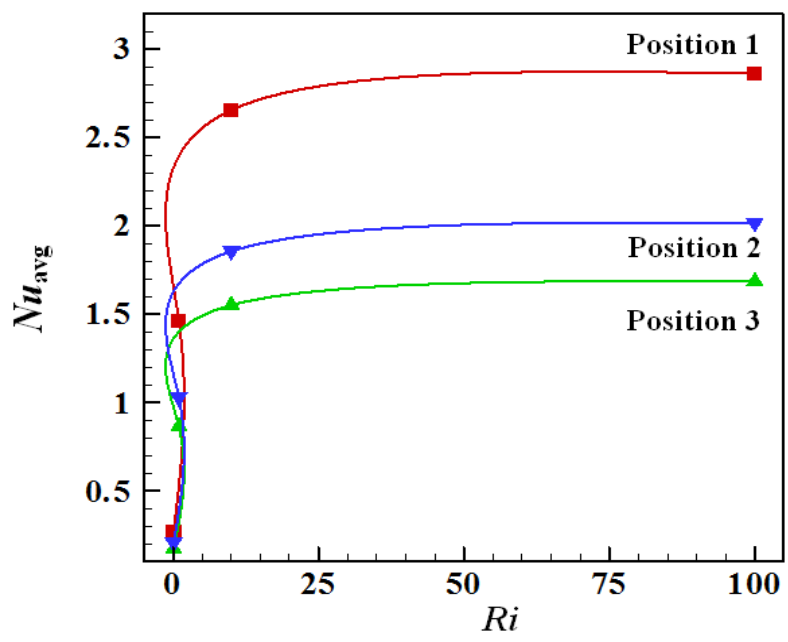

Fig.11 Variation of the average Nusselt number with the Ri for the positions 1, 2 and 3 of heat source.

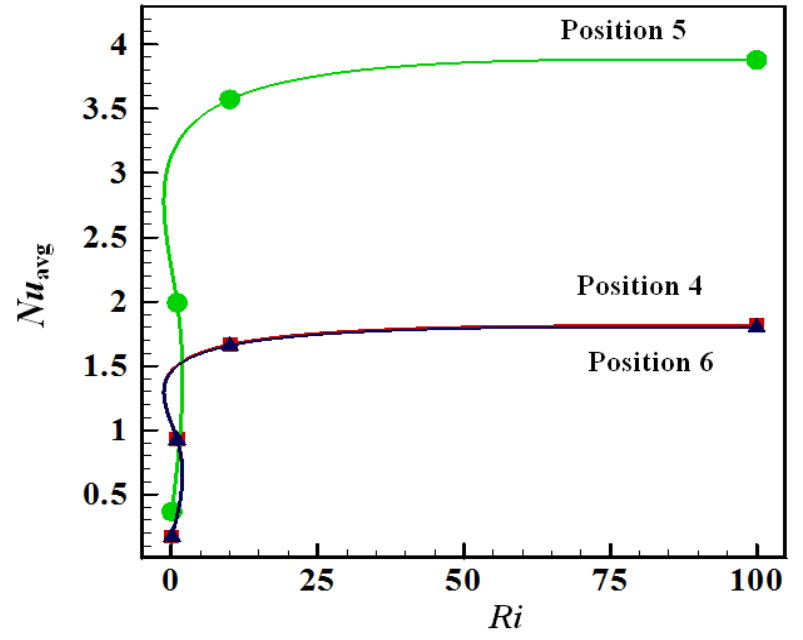

Fig. 12 Variation of the average Nusselt number with the Ri for the positions 4,5 and 6 of heat source.

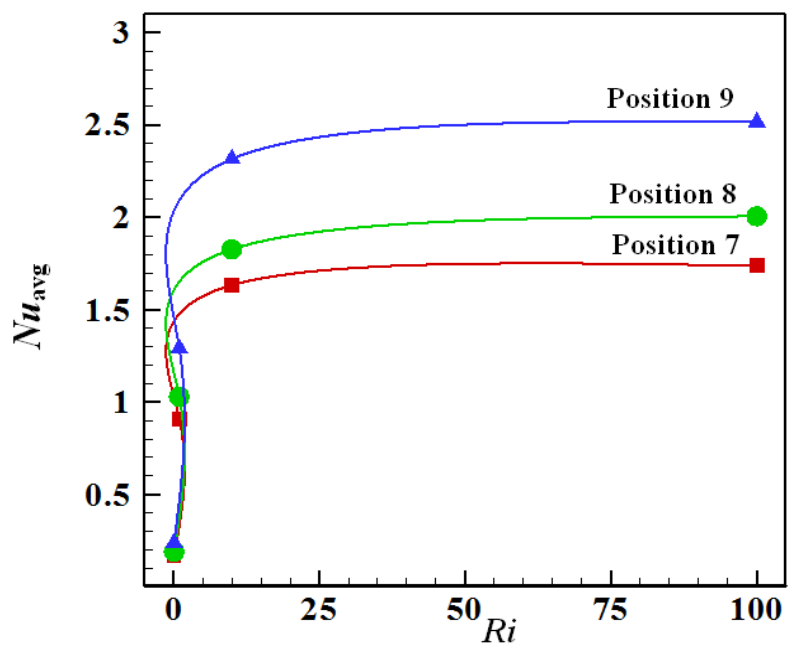

Fig. 13 Variation of the average Nusselt number with the Ri for the positions 7, 8 and 9 of heat source.

Table 1. Average Nusselt number for various Richardson number and heat source positions.

\begin{tabular}{|c|c|c|c|c|}
\hline Post.5 & Post.6 & Post.7 & Post. 8 & Post. 9 \\
\hline 0,36708165 & 0,17368284 & 0,16780391 & 0,18975639 & 0,23797453 \\
\hline 1,99150944 & 0,92438607 & 0,91037831 & 1,02947545 & 1,29107074 \\
\hline 3,57237445 & 1,65816503 & 1,63303869 & 1,82693644 & 2,31592623 \\
\hline 3,88040057 & 1,80113977 & 1,73756879 & 2,00590409 & 2,51561606 \\
\hline
\end{tabular}




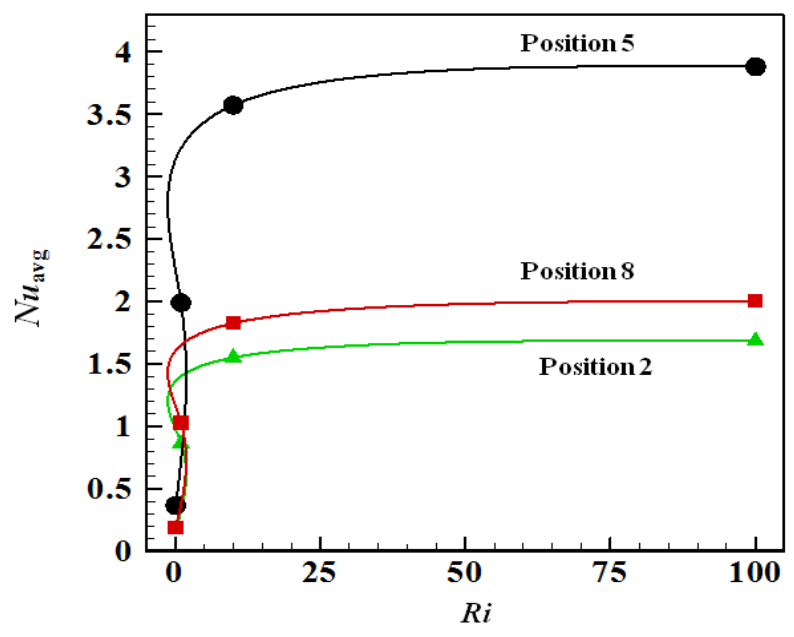

Fig. 14 Variation of the average Nusselt number with the Ri for the positions 2,5 and 8 of heat source.

To find the ideal position of the heat source, we are compared three positions of the heat sources 2, 5 and 8 to choose the best heat transfer (see Figure 14). We have noticed that the best heat transfer is at position 5, where the heat source is placed in the top of the left wall of the open cavity.

\section{Conclusion}

A numerical investigation of heat transfer in a horizontal channel with an open trapezoidal cavity arranged with various locations of heat source is carried out. The following conclusions are deduced.

- The best heat transfer is found when the heat source is placed in the top of the left wall.

- The average Nusselt number increases as the Richardson number increases.

\section{References}

1. F. Mebarek-Oudina, R. Bessaïh, Int. Rev. Physics, 4, 45 (2010).

2. F. Mebarek-Oudina, R. Bessaïh, J. Frank. Inst, 351, 667 (2014).

3. F. Mebarek-Oudina, R. Bessaïh, J. Appl. Fluid Mech, 9, 1655 (2016).

4. F. Mebarek-Oudina, Eng. Sci. Tech 20, 1324 (2017)

5. F. Mebarek-Oudina, O. Makinde, Defect Diff. Forum, 387, 417 (2018).

6. F. Mebarek-Oudina, Heat Transf. Asian Res., 48, 135 (2019).

7. J. Raza, M. Farooq, F. Mebarek-Oudina, B. Mahanthesh, Mult. Model. Materials Struc., 15, 913 (2019).

8. J. Raza, F. Mebarek-Oudina, B. Mahanthesh, Mult. Model. Materials Struc., 5, 871 (2019).

9. J. Raza, F. Mebarek-Oudina, A.J. Chamkha, Mult. Model. Materials Struc., 15, 737 (2019).
10. M. Alkasassbeh, Z. Omar, F. Mebarek-Oudina, J. Raza, A. Chamkha, Heat Transf. Asian Res., 48, 1225 (2019).

11. F. Mebarek-Oudina, R. Bessaïh, Therm. Aerom., 26, 334 (2019).

12. S. Gourari, F. Mebarek-Oudina, A.K. Hussein, L. Kolsi W. Hassen O. Younis, Int. J. Heat Tech, 37, 779 (2019).

13. H. Laouira, F. Mebarek-Oudina, A.K. Hussein, L. Kolsi, A. Merah, O. Younis, Heat Transf. Asian Res., 1 (2019)

14. O. Manca, S. Nardini, K. Khanafer, K. Vafai, Numerical Heat Transfer - Part A, Vol. 43, No. 3, 2003, pp : 259-282.

15. O. Manca, S. Nardini, K. Vafai, Exp. Heat Transfer, 19, 53 (2006).

16. O. Manca, S. Nardini, K. Vafai, Exp. Heat Transfer, 21, 99 (2008).

17. S. Aminossadati, B.A. Ghasemi, Europ. J. Mech. B/Fluids, 28, 590 (2009).

18. B. Buonomo, G. Cresci, O. Manca, P. Mesolella, J. Physics, 395, 1 (2012).

19. W. Sabbar, M. Ismael, M. Al-Mudhaffar, Int. J. Mech. Sci., 149, 73 (2018).

20. F. Garcia, C. Trevino, J. Lizardi, Int. J. Mech. Sci., 155, 295 (2019).

21. T. Fusegi, Int. J. Heat Fluid Flow, 18, 376 (1997).

22. O. Manca, S. Nardini, V. Naso, R. Pitzolu, Measur. Visual, Sorrento, Italy, (2003).

23. J. Leong, N. Brown, F. Lai, Int. Commun. Heat Mass Transf., 32, 583 (2005).

24. N. Brown, F. Lai, Int. Commun. Heat Mass Transf., 32, 1000 (2005).

25. M. Rahman, S. Parvin, N. Rahim, M. Hasanuzzaman, R. Saidur, Heat transf. Asian res. 41, 339 (2012).

26. Y. Stiriba, F. Grau, J. Ferre, A.A. Vernet, Int. J. Heat Mass Transf., 53, 4797 (2010).

27. A. Azad, M. Munshi, M. Rahman, M. Chowdhury, J. Sci. Res., 6, 243 (2014).

28. F. Zamzari, Z. Mehrez, A. El-Cafsi, A., Belghith, P. P. Quéré, J. Hydro., 29, 632 (2017).

29. H. Contreras, C. Trevino, J. Lizardi, L. MartinezSuastegui, Int. J. Mech. Sci., 150, (2019), 427. 